\title{
Influence of superabsorbent polymers on hydration of cement pastes with low water-to-binder ratio
}

\author{
Journal Article \\ Author(s): \\ Justs, Janis; Wyrzykowski, Mateusz; Winnefeld, Frank; Bajare, Diana; Lura, Pietro \\ Publication date: \\ 2014 \\ Permanent link: \\ https://doi.org/10.3929/ethz-b-000080493
}

Rights / license:

In Copyright - Non-Commercial Use Permitted

Originally published in:

Journal of Thermal Analysis and Calorimetry 115(1), https://doi.org/10.1007/s10973-013-3359-x 


\title{
Influence of superabsorbent polymers on hydration of cement pastes with low water-to-binder ratio
}

\author{
A calorimetry study
}

\author{
Janis Justs • Mateusz Wyrzykowski • \\ Frank Winnefeld $\cdot$ Diana Bajare $\cdot$ Pietro Lura
}

Received: 8 January 2013 / Accepted: 2 August 2013/Published online: 29 August 2013

(C) Akadémiai Kiadó, Budapest, Hungary 2013

\begin{abstract}
Internal curing with superabsorbent polymers (SAP) is a method for promoting hydration of cement and limiting self-desiccation, shrinkage and cracking in highperformance, and ultra high-performance concrete with low water-to-binder ratio. SAP are introduced in the dry state during mixing and form water-filled inclusions by absorbing pore solution. The absorbed solution is later released to the cement paste during hydration of the cement. In this paper, cement pastes with low water-tobinder ratios incorporating superplasticizer and different dosages of SAP and corresponding additional water were prepared. Reference cement pastes without SAP but with the same amount of water and superplasticizer were also mixed. Isothermal calorimetry was used to measure hydration heat flow. Water entrainment by means of SAP increased the degree of hydration at later hydration times in a manner similar to increasing the water-to-binder ratio. Addition of SAP also delayed the main calorimetric hydration peak compared to the reference pastes, however,
\end{abstract}

J. Justs · M. Wyrzykowski · F. Winnefeld · P. Lura Empa, Swiss Federal Laboratories for Materials Science and Technology, Dübendorf, Switzerland

J. Justs $(\square) \cdot$ D. Bajare

Institute of Materials and Structures, Riga Technical University, Riga, Latvia

e-mail: janis.justs@rtu.lv

\section{Wyrzykowski}

Department of Building Physics and Building Materials, Lodz University of Technology, Lodz, Poland

P. Lura

Institute for Building Materials (IfB), ETH Zurich, Zurich, Switzerland in a less prominent manner than the increase in water-tocement ratio.

Keywords Superabsorbent polymers (SAP) . Cement hydration · Isothermal calorimetry $\cdot$ Portland cement . Low water-to-binder ratio

\section{Introduction}

Superabsorbent polymers (SAP) are covalently crosslinked hydrophilic polyelectrolytes with three-dimensional structures that absorb high amounts of liquid without dissolving and retain the liquid even under a certain pressure [1]. In concrete technology, SAP have been applied, e.g., for frost resistance improvement, rheology modification, controlled release of admixtures, crack healing, water curing from the concrete surface and reducing the coefficient of thermal expansion [2-5].

One of the most promising application areas for SAP is internal curing of high-performance concrete (HPC) and ultra high-performance concrete (UHPC) [2, 3]. These modern concretes develop very high mechanical properties due to their extremely low porosity. Their low porosity makes them also almost impermeable, which is beneficial for their durability. However, HPC and UHPC experience rapid and high shrinkage in the first days to weeks of hydration, which may induce micro- or macro-cracks and affect negatively their durability.

Typically, HPC and UHPC are characterized by a dense packing of the aggregate, small maximum aggregate size, low water-to-cement ratios $(w / c)$, and often addition of fine fillers or supplementary cementitious materials (e.g., silica fume). Due to the low $w / c$, complete hydration of cement cannot be reached. The final degree of hydration, defined as 
the amount of cement hydrated relative to the initial cement, is thus lower than 1. Cement hydration stops due to lack of free water and also due to lack of free pore space for forming new hydration products [6]. The final degree of hydration in a low $w / c$ paste can be estimated by means of Powers' model [2, 6-9], which was originally formulated in the late 1940s. Powers' model, despite its simplicity and the fact that the exact numbers need to be reviewed for applying for modern cements [7], has proven to give reliable predictions about final degree of hydration and volumetric distribution of phases in cement pastes.

In order to promote the hydration, additional water may be provided, which is referred to as curing water in concrete practice. In HPC and UHPC, it is convenient to provide curing water as small inclusions within the concrete, for example within well-distributed SAP [10, 11]. In very low $w / c$ pastes, even if (internal) curing water is provided, hydration can be enhanced but not completed due to dense packing of unhydrated cement and hydration products and limited space for new hydration products to form.

Other effects of insufficient water for hydration in low $w / c$ pastes are self-desiccation and autogenous shrinkage. As cement hydrates in a sealed system, the largest pores in the hardening cement paste become empty, since the hydration products have lower volume than the unhydrated cement and water (chemical shrinkage) [9]. The menisci at the interface between air and pore fluid become smaller and smaller as the pore structure fills up with hydration products. As a consequence, the internal relative humidity (RH) decreases (self-desiccation) and capillary stresses build up in the pore fluid. The result is a compressive stress on the porous skeleton that induces a macroscopic shrinkage (autogenous shrinkage) [9]. Addition of SAP is also useful to reduce self-desiccation and autogenous shrinkage, as the degree of saturation of the capillary pores in the cement paste remains higher and the capillary stresses decrease accordingly [10,11].

SAP are added in the dry state during mixing, whereupon they rapidly absorb part of the mixing water and form water-filled cavities (about 100-500 $\mu \mathrm{m}$ in diameter) in the fresh concrete [3, 4]. To compensate for self-desiccation, the amount of water absorbed by the SAP needs to be added to the mixing water [2]. After setting, SAP are progressively emptied as they lose water to the paste to compensate for the chemical shrinkage [12]. The water release by the SAP keeps a high internal RH in the cement paste, which reduces the capillary stresses and the shrinkage and also promotes the hydration [3, 13]. It is noticed that, depending on the chemical composition of the SAP, the kinetics of the pore solution release may change, possibly resulting even in a premature emptying before setting [14].
Since the SAP after releasing water end up as partially empty pores in the cement paste, they might impact negatively the mechanical properties, similarly as entrained air voids [3]. However, the presence of these large pores is at least in part compensated by a higher degree of hydration, which reduces the porosity of the cement paste $[3,4,15]$. As a result, the strength does not necessarily decrease due to addition of SAP, and even some strength gain has been observed at later ages in respect to reference mixtures $[15,16]$. By knowing the degree of hydration of the cement in a mixture containing SAP, it is possible to predict the compressive strength of the concrete with reasonable approximation based on its porosity [15].

The main focus of this paper is to understand the influence of SAP on the hydration process. Isothermal calorimetry is a convenient and precise method to study the early stage of hydration of cement pastes, when the heat release rate is high [17-19]. This study focuses on the effect of SAP on the kinetics of hydration of low $w / c$ pastes. Nine plain cement pastes with $w / c$ ratios $0.20-0.30$, with and without SAP and with constant superplasticizer amount (1\% of cement mass), were investigated.

\section{Materials and methods}

\section{Mix composition}

White Portland cement (CEM I 52.5 R) was used in this study. Table 1 shows the chemical composition of the cement with the normative composition determined with a modified Bogue calculation [20]. A commercial polycarboxylate-based superplasticizer with $22 \%$ solid content and specific gravity of 1.04 was used for all mixtures. Solution-polymerized SAP of irregular particle shape and particle sizes $<63 \mu \mathrm{m}$ in the dry state were used. Absorption of pore solution by SAP was determined as equal to $16 \mathrm{gg}^{-1}$ based on the ratio occupied by the swollen SAP on polished sections of hardened cement pastes [21]. A neutron tomography study confirmed that this type of SAP starts releasing water only after setting [22].

To investigate early age hydration, cement pastes with SAP and reference pastes without SAP but with exactly the same amount of water and superplasticizer were prepared. The reference mixture had $w / c 0.20$, which corresponds to the basic $w / c$ of the pastes with SAP. In the figures, all mixtures are labeled by $w / c$. Mixtures containing SAP are labeled according to the following convention: 0.25 SAP means $0.20+0.05$, where 0.05 is $w / c$ entrained by SAP and 0.20 is basic $w / c$. The range of $w / c$ was $0.2-0.3$. The superplasticizer ( $1 \%$ of cement mass for all cement pastes) was added to the pastes without correction for water content. 
Table 1 Chemical properties of Portland cement

\begin{tabular}{|c|c|c|c|}
\hline \multicolumn{2}{|c|}{ Chemical analysis/mass/\% } & \multicolumn{2}{|c|}{ Normative phase composition/mass/\% } \\
\hline $\mathrm{SiO}_{2}$ & 24.33 & Alite & 77.5 \\
\hline $\mathrm{Al}_{2} \mathrm{O}_{3}$ & 2.07 & Belite & 14.3 \\
\hline $\mathrm{Fe}_{2} \mathrm{O}_{3}$ & 0.36 & Aluminate & 2.8 \\
\hline $\mathrm{CaO}$ & 69.02 & Ferrite & 0.1 \\
\hline $\mathrm{MgO}$ & 0.64 & $\mathrm{CaO}$ & 0.85 \\
\hline $\mathrm{SO}_{3}$ & 2.04 & $\mathrm{CaCO}_{3}$ & 0.16 \\
\hline $\mathrm{K}_{2} \mathrm{O}$ & 0.04 & $\mathrm{CaSO}_{4}$ & 3.3 \\
\hline $\mathrm{Na}_{2} \mathrm{O}$ & 0.15 & $\mathrm{~K}_{2} \mathrm{SO}_{4}$ & 0.07 \\
\hline $\mathrm{CaO}$ (free) & 0.85 & $\mathrm{Na}_{2} \mathrm{SO}_{4}$ & 0.15 \\
\hline $\mathrm{TiO}_{2}$ & 0.07 & $\mathrm{~K}_{2} \mathrm{O}$ & 0.002 \\
\hline $\mathrm{Mn}_{2} \mathrm{O}_{3}$ & 0.02 & $\mathrm{Na}_{2} \mathrm{O}$ & 0.1 \\
\hline $\mathrm{P}_{2} \mathrm{O}_{5}$ & 0.36 & $\mathrm{MgO}$ & 0.64 \\
\hline L.o.I. & 0.77 & & \\
\hline
\end{tabular}

Normative phase composition calculated with modified Bogue method [20]

L.o.I. Loss on ignition

\section{Mixing}

All nine pastes were mixed in a vacuum mixer (Twister evolution) at $450 \mathrm{rpm}$. The first step of dry mixing was $30 \mathrm{~s}$ for all mixtures. In the next step, $90 \%$ of the water was added and mixed for $1.5 \mathrm{~min}$. In the last step, the rest of the water and superplasticizer was added, and the pastes were mixed further for a maximum of $3 \mathrm{~min}$.

\section{Hydration heat}

The heat flow was measured with a Thermometric TAM Air conduction calorimeter, capable of eight parallel measurements in eight separate measuring cells. About $5.4 \mathrm{~g}$ of freshly mixed paste were weighed into a glass vial of internal diameter $24.5 \mathrm{~mm}$, corresponding to $\sim 5$ - $\mathrm{mm}$ thick paste layer. The glass vial was sealed and placed into the calorimeter and the heat flow was measured for about $72 \mathrm{~h}$. The very low $w / c$ used required external mixing, for which reason the initial heat peak, occurring right after the addition of water to cement, could not be measured. During the experiment, isothermal conditions $\left(20 \pm 0.02{ }^{\circ} \mathrm{C}\right)$ were maintained in the measuring cells. The hydration heat flow and the cumulative hydration heat, normalized to the cement mass in the samples, are shown in the results section starting from $1 \mathrm{~h}$ after water addition, allowing time for temperature equilibration.

To determine the heat release upon contact of cement with water (which could not be observed because of external mixing), the $w / c 0.30$ paste was also mixed directly in the calorimeter after thermal equilibration. The cumulative heat release during the initial first hour after mixing did not exceed $6 \mathrm{Jg}^{-1}$.
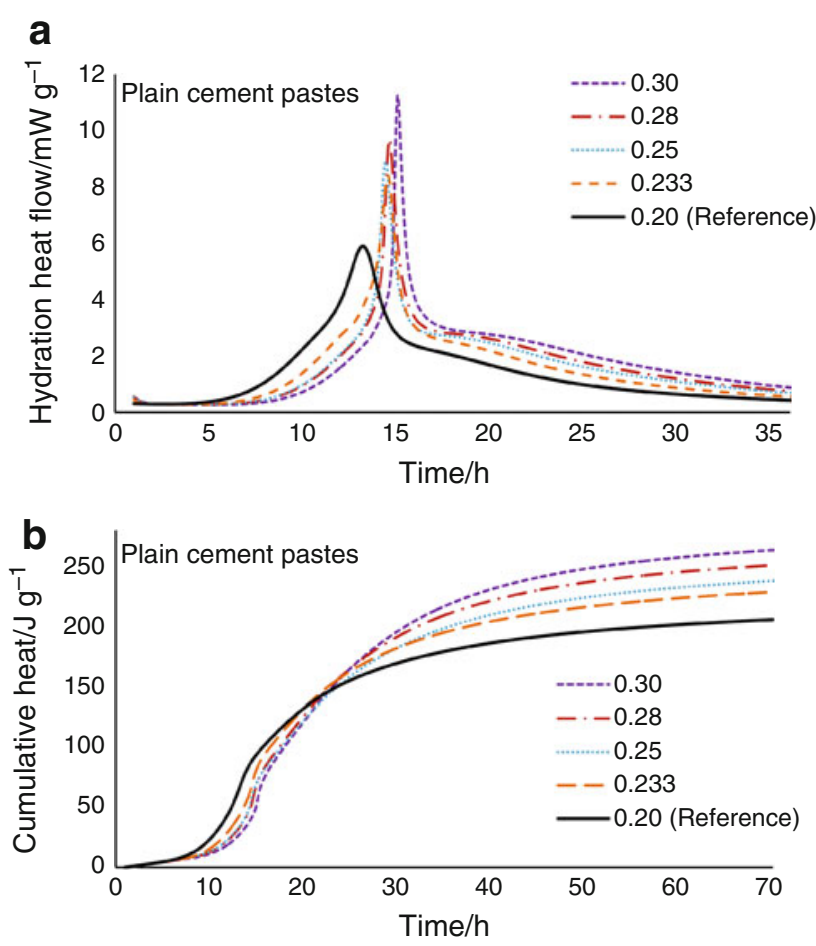

Fig. 1 a Hydration heat release rate (until 36 h) and b cumulative heat (until $72 \mathrm{~h}$ ) of plain cement pastes

The degree of hydration at a certain age is calculated as the ratio between the cumulative heat of hydration at that age and the heat released at full hydration (potential heat of hydration). The latter value was calculated by thermodynamical modelling using the geochemical software GEMSPSI [23] coupled with the thermodynamic database CEMDATA 07.2 [24]. After subtracting the total enthalpies of the simulated products from the constituents, the total heat at full hydration is determined as $473 \mathrm{Jg}^{-1}$. This value is further used for determining the degree of hydration.

\section{Results}

In Figs. 1 and 2 the rate of heat of hydration and cumulative heat are presented as influenced by the different amounts of neat additional water, or water in the SAP reservoirs, respectively. For the reasons of clarity, the heat flow results are plotted up to $36 \mathrm{~h}$ only, while for the cumulative heat the whole measuring period of $72 \mathrm{~h}$ is shown. A dormant period of 5-7 h (depending on the $w / c$ [25] and on the superplasticizer dosage [26]) is followed by a main heat rate peak [27] between 13 and $15 \mathrm{~h}$. For pastes without SAP, the main heat release peaks are delayed as $w / c$ increased. In general, the height of the main peaks also increases with $w / c$. Addition of SAP has a 

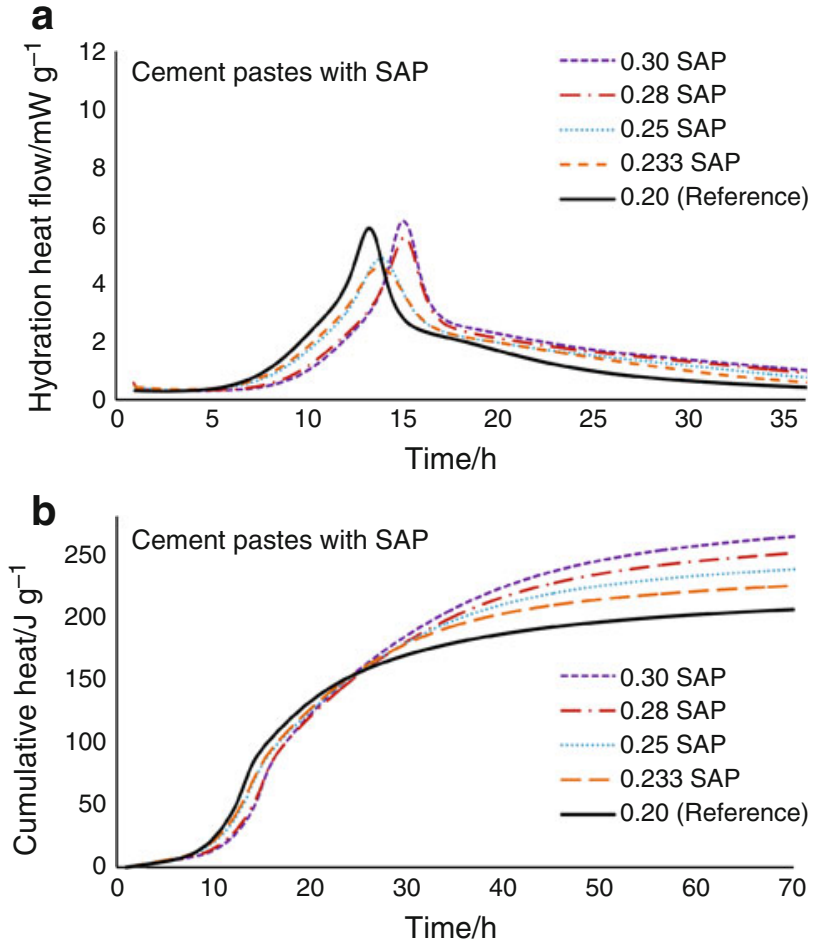

Fig. 2 a Hydration heat release rate (until $36 \mathrm{~h}$ ) and b cumulative heat (until $72 \mathrm{~h}$ ) of cement pastes with SAP

significant impact on the hydration behavior of the cement pastes. The main peaks are lower and appear earlier compared to the corresponding pastes with the same $w / c$ but without SAP (Figs. 1a, 2a). On the other hand, the main peaks are delayed compared to the reference paste containing the same amount of free water (excluding the water incorporated in the SAP). The heights of the main peaks are similar for different SAP contents. Only a slight delay of the main hydration heat peak is observed by increasing the SAP content. In general, the shape of the main peak is very similar for all pastes with and without SAP, while a shoulder of substantially lower heat flow following the main peak is clearly visible for plain pastes only.

The cumulative heat of hydration (Fig. 1b) increases with increasing $w / c$. However, more important for this study is the comparison between pastes with and without SAP. All pastes containing SAP reach higher hydration heat values than the reference paste. The cumulative heat of hydration of pastes with SAP exceeds that of the reference paste after about $24 \mathrm{~h}$. Comparing the same $w / c$ pastes with and without SAP, it can be seen that the main hydration reaction of pastes with SAP starts earlier but proceeds at a slower rate than for the pastes without SAP, while the cumulative heat release after 3 days is similar. In Fig. 3, the heat release rate and the cumulative heat is compared for the reference mixture of $w / c 0.20$ and for the $w / c$ increased to 0.25 , either by adding neat water or
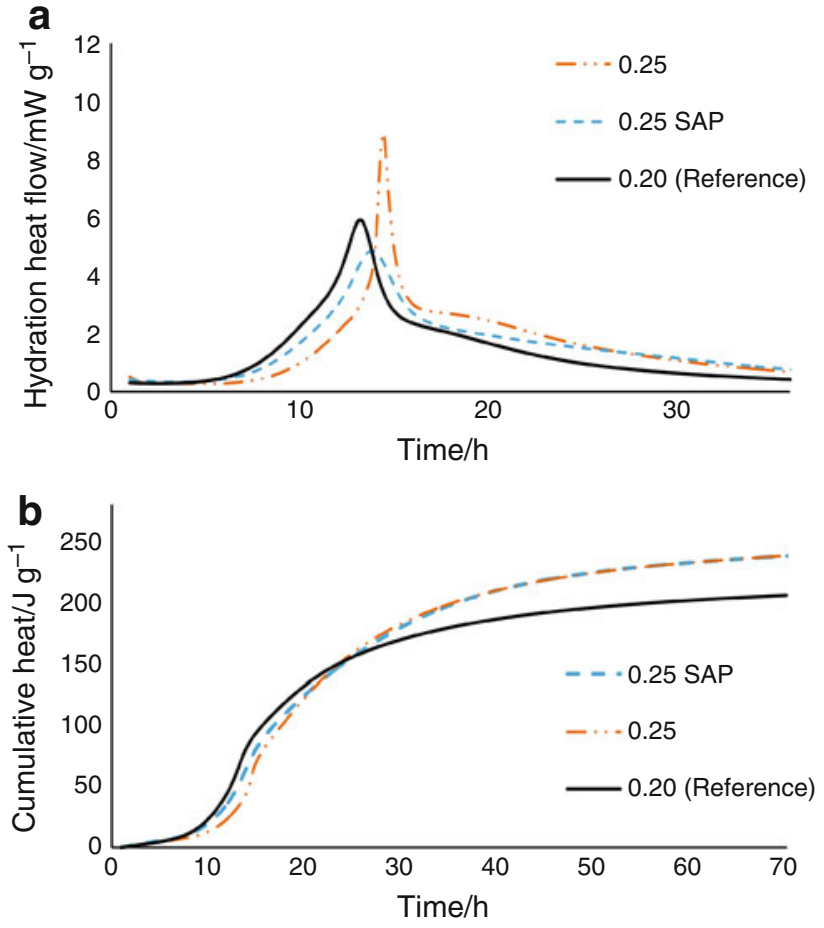

Fig. 3 Comparison of the reference mixture $(w / c$ 0.20) to the mixtures of $w / c$ increased to 0.25 , either by adding neat water or by adding water absorbed within SAP. a Hydration heat release rate (until $36 \mathrm{~h}$ ) and b cumulative heat (until $72 \mathrm{~h}$ )

by adding water absorbed within SAP. Increasing $w / c$ by adding neat water results in much higher and sharper main heat release peaks, while $w / c$ increases by means of SAP gave lower and broader peaks compared to the reference.

\section{Discussion}

\section{Early hydration}

In this section, the influence of SAP on initial hydration is discussed. This period is especially important in terms of the setting time and strength development. A retardation of the setting time may have consequences for the practical use of UHPC, as setting time is already delayed by the high superplasticizer content of these mixtures and a further retardation may not be acceptable. Moreover, a rapid strength development at early ages is often also fundamental for the application of UHPC, so that even if SAP are introduced into the mixture, they should not be overly detrimental for the early strength. As both SAP and additional water to saturate them are introduced into the mixtures with internal curing, it is necessary in this analysis to separate the effect of the SAP on the early hydration from that of an increase in the $w / c$ of the pastes. 
In the present experiments, it is observed that a retardation of the main calorimetric peak always accompanied the increase in $w / c$ (Figs. 1, 2). Zhang et al. [19] also observed that an increase of $w / c$ delayed the main hydration peak and increased the total degree of hydration at later ages. Danielson [28] suggested that an increase in the rate of heat liberation with decreasing $w / c$ during the first hours of hydration could be explained by a higher concentration of alkalis in the pore solution. In fact, the soluble alkalis in the cement lead to a rapid pH rise that is known to accelerate cement hydration. This acceleration is directly dependent on the alkali concentration, which is in turn inversely dependent on the $w / c$. In other words, by increasing the $w / c$ the initial pore solution becomes diluted with respect to alkali and hydroxide ions, and this provides less acceleration of cement hydration. As in this study lowalkali cement was used (see Table 1), the effect of retardation with increased $w / c$ is expected to be even more pronounced than for a normal Portland cement.

The isothermal calorimetry data, Figs. 1 and 2, show that the addition of SAP radically modifies the hydration kinetics of cement pastes, especially in the first $30 \mathrm{~h}$. The trend observed is of a small delay of the first peak of hydration heat for samples containing SAP compared to the reference paste and an even smaller delay between pastes with increasing SAP contents. However, in all cases the main hydration heat peak occurs earlier compared to the corresponding pastes with the same water amount but without SAP. A more pronounced shoulder appears after the main peak with higher SAP additions, possibly indicating a release of entrained water from the SAP. Another possible reason is the influence of SAP on the kinetics of the second aluminate reaction; the SAP may possibly provide additional water for the formation of ettringite.

In all cases, the cumulative heat of hydration and consequently the calculated final degree of hydration at 3 days increased by increasing SAP and entrained water amount (Figs. 1, 2).

A possible reason of the small retardation of the main peak with SAP may be a delay in the onset of the acceleration period due to leaching of some non-cross-linked polymers from the SAP [3]. These linear polymers (also indicated as soluble fraction) are a byproduct of the SAP synthesis and may interfere to a certain extent with cement hydration. Another possibility, compatible with Danielson's hypothesis [28] explained above, is that the SAP absorb some alkali ions with the pore solution during mixing [29], thus diluting the initial ion concentration in the mixing water and delaying the main hydration heat peak. According to this hypothesis, the water in the SAP would behave like a separate phase until about setting time, with little ion exchange with the water in the capillary pores of the cement paste.
The fact that the main peak for mixtures with SAP occurs between that for the reference paste and that for the paste with only water added can be explained with the desorption kinetics of SAP. The water held in the SAP up to setting time is then gradually released as pores in the cement paste are emptied by chemical shrinkage and capillary forces build up that pull the water from the SAP $[3,11,12,22]$. Therefore, not all water is instantaneously available as in the case of increased $w / c$ with neat water, and thus the pastes with SAP show an earlier main hydration peak.

\section{Late hydration}

This section addresses the influence of SAP addition on the ultimate degree of hydration. The ultimate degree of hydration influences the strength at later ages (days to months after casting), which needs to be decreased as little as possible by SAP addition. While SAP addition introduces additional porosity in the cement paste, hydration proceeding further than in the reference paste helps compensating in part for the initial additional porosity and limits the strength loss at later ages.

Pastes containing SAP after 3 days of hydration reach a similar cumulative heat value to the corresponding pastes with the same $w / c$, where the $w / c$ in the case of SAP specimens includes also the water introduced within the SAP (see Fig. 3b). This leads to the conclusion, the water introduced within the SAP has a similar effect on the final values of the hydration degree as a simple increase of the $w / c$ ratio, Table 2 . It also suggests that most likely all the water was released from the SAP by the age of 3 days. Naturally, if one compares the cement pastes with SAP to the reference paste of the same basic $w / c$ of 0.20 , a promotion of hydration is clearly visible.

The maximum degree of hydration in sealed and saturated Portland cement pastes of different $w / c$ can be calculated with Powers' model [6-8]. Jensen and Hansen [2] applied Powers' model to calculate the amount of internal curing water necessary to avoid self-desiccation in pastes with SAP. They considered them as saturated cement pastes where hydration stops due to filling-up of capillary pores with hydration products, even if there would still be free water available for hydration to proceed.

Following Powers' model, the maximum degree of hydration $\alpha_{\max }^{\text {sat }}$, of a Portland cement paste with free access to external water (open or saturated system) is limited by the volume of capillary pores that is available for the hydration products to form. When capillary porosity becomes zero, the maximum hydration degree is given as [8]: 
$\alpha_{\max }^{\mathrm{sat}}=\frac{w_{0} / c}{\left(V_{\mathrm{n}}+a \cdot k\right) \cdot w_{\mathrm{n}}^{0} / c} \leq 1$

where $w_{0} / c$ is the initial $w / c$ of the paste; $V_{\mathrm{n}} \cong 0.75 \mathrm{~cm}^{3} \mathrm{~g}^{-1}$ is the specific volume of non-evaporable water; $a \cong 4$, the number of water monolayers adsorbed on the hydration products at RH $100 \% ; w_{n}^{0} / c$ is the non-evaporable water content per gram of cement hydrated; $k$ corresponds to the ratio between the mass of water necessary to cover the hydrated cement with one monolayer $\left(V_{\mathrm{m}}\right.$ in [6]) and the non-evaporable water, which is also cement-specific.

Unlike in [8], and following Brouwers [7], $a$ was assumed as 4 in Eq. (1), which is closer to modern estimations by a number of researchers (see [7]) than the value of 3.3 used originally in [6].

On the other hand, the maximum degree of hydration $\alpha_{\max }^{\text {sea }}$ of a Portland cement paste with no access to external water (sealed system), where the hydration stops due to the lack of water available for the reaction, can be calculated as [8]:

$\alpha_{\max }^{\text {sea }}=\frac{w_{0} / c}{(1+a \cdot k) \cdot w_{\mathrm{n}}^{0} / c} \leq 1$.

It is noticed that the degree of hydration in sealed conditions is always lower than that in saturated conditions.

According to Brouwers [7], employing average values for $k$ and $w_{n}^{0} / c$ in Powers' model (e.g., $[2,8]$ ), which were derived from measurements of Portland cements from the 1940s, may not be valid for modern cements that are higher in alite, and especially for white Portland cements. As pointed out by Brouwers [7], the cements used by Powers and Bownyard [6] had a phase composition quite different from modern Portland cement; in particular, their alite content was substantially lower (average of $47 \%$ alite for 38 different cements, with only two cements having alite content above $60 \%$; see Table 1 reported in [7]). Moreover, the white cement used in our study has a very low $\mathrm{C}_{4} \mathrm{AF}$ content comparing to the grey cements. Thus, in this study the coefficients in Powers' model were estimated for the composition of the cement used, Table 1, according to the empirical relations by Powers and Brownyard $[6,7]$ :

$$
\begin{aligned}
k= & 0.230 \cdot C_{3} S+0.320 \cdot C_{2} S+0.317 \cdot C_{3} A+0.368 \\
& \cdot C_{4} \mathrm{AF}
\end{aligned}
$$

where $C_{3} S, C_{2} S, C_{3} A, C_{4} \mathrm{AF}$ are the mass fractions of the major clinker phases in the cement. For the used white Portland cement, Eq. (3) yields $k$ equal to 0.233.

For calculating the non-evaporable water content, the following equation was used:

$w_{\mathrm{n}}^{0} / c=a_{1} \cdot C_{3} S+a_{2} \cdot C_{2} S+a_{3} \cdot C_{3} A+a_{4} \cdot C_{4} \mathrm{AF}$
Table 2 Degree of hydration determined with calorimetry at 3 days compared with predictions of ultimate degree of hydration by Powers' model

\begin{tabular}{lll}
\hline Mixture & $\begin{array}{l}\text { Hydration } \\
\text { degree measured } \\
\text { at } 3 \text { days }\end{array}$ & $\begin{array}{l}\text { Ultimate hydration } \\
\text { degree predicted } \\
\text { with Powers' model }\end{array}$ \\
\hline$w / c 0.20$ & 0.45 & 0.56 \\
$w / c 0.233$ & 0.50 & 0.65 \\
$w / c 0.233 \mathrm{SAP}$ & 0.50 & 0.65 \\
$w / c 0.25$ & 0.52 & 0.69 \\
$w / c 0.25 \mathrm{SAP}$ & 0.52 & 0.69 \\
$w / c 0.28$ & 0.54 & 0.78 \\
$w / c 0.28 \mathrm{SAP}$ & 0.54 & 0.78 \\
$w / c 0.30$ & 0.57 & 0.83 \\
$w / c 0.30 \mathrm{SAP}$ & 0.57 & 0.83 \\
\hline
\end{tabular}

where $a_{1}, \ldots, a_{4}$ are the values of non-evaporable water for single phases. These values are usually determined by fitting the parameters to the experimentally determined nonevaporable water content determined for the whole hydrated cement paste. Using a set of coefficients determined originally by Powers and Brownyard [6] $\left(a_{1}=0.187, a_{2}=0.158, a_{3}=0.665, a_{4}=0.213\right)$, yields for the cement composition presented in Table 1 a nonevaporable water content of $0.186 \mathrm{~g} / \mathrm{g}$ of cement reacted. As observed already by Powers and Brownyard [6], the original samples used for determining the set of parameters $a_{1}, \ldots, a_{4}$ may have not been fully hydrated, which would lead to underestimation of non-evaporable water content. However, the model by Powers and Brownyard already compensates for this incomplete hydration.

By taking into account the actual cement composition, for saturated systems a $w / c$ of 0.31 would be sufficient to reach full hydration (Eq. 1), while this figure would rise to 0.36 for sealed systems (Eq. 2). On the other hand, using average values of the parameters, i.e., $a=3.3, k=0.25$ and $w_{n}^{0} / c=0.23$, valid for cements used by Powers and Brownyard [6,7], one would find the much higher values of 0.36 for saturated systems (Eq. 1) and 0.42 for sealed systems (Eq. 2) [2, 8]. At the same time, it should be underlined that extrapolating Powers' model to cement compositions that are far from those tested originally in [6] may lead to some errors.

The maximum degree of hydration according to the adjusted calculations with Powers' model is presented in Table 2 together with the degree of hydration calculated at 3 days from calorimetry. While the degree of hydration of the plain cement pastes can be calculated with Eq. (2) (sealed systems), the degree of hydration of the pastes with SAP should be calculated with Eq. (1) (open systems), provided that a sufficient amount of water is entrained in 
the form of water reservoirs formed by the swollen SAP [2]. It is noticed that the relation between measured degrees of hydration up to 3 days between specimens with and without SAP and between different $w / c$ appears to be in good agreement with the model predictions for the ultimate degree of hydration (Table 2), both for plain pastes and pastes with SAP.

\section{Conclusions}

Addition of SAP has a significant impact on the hydration behavior of cement pastes with low $w / c$. The main hydration peaks in the isothermal calorimeter are lower and appear earlier compared to the corresponding pastes with the same $w / c$ ratio but without SAP. This originates from the gradual release of water from SAP as the hydration and corresponding chemical shrinkage proceed. On the other hand, the main peaks are slightly delayed compared to the reference cement pastes containing the same amount of free water. Possible explanations of this behavior are leaching of linear polymers (soluble fraction) from the SAP that might interfere with hydration and absorption of alkali ions into the SAP.

Water entrainment by means of SAP increases the degree of hydration at later times in a manner similar to a simple increase of the $w / c$. Predictions of the final degree of hydration can be obtained with Powers' model, provided the coefficients in the model are calculated based on the actual phase composition of the cement. These predictions represent the same trend as the degree of hydration at 3 days calculated from isothermal calorimetry.

Acknowledgements This study was funded by Scientific Exchange Programme NMS-CH under the project "ASPIRE-Autogenous shrinkage and early age behavior of high and ultra-high performance concrete". The superabsorbent polymers used in this study were provided by Dr. Gregor Herth and Dr. Stefan Friedrich from BASF Construction Chemicals GmbH.

\section{References}

1. Buchholz FL, Graham AT. Modern superabsorbent polymer technology. New York: Wiley VCH; 1997.

2. Jensen OM, Hansen PF. Water-entrained cement-based materials: I. Principles and theoretical background. Cem Concr Res. 2001;31(4):647-54.

3. Jensen OM, Hansen PF. Water-entrained cement-based materials II. Experimental observations. Cem Concr Res. 2002;32(6):973-8.

4. Mechtcherine V, Reinhardt H-W. Application of super absorbent polymers (SAP) in concrete construction. RILEM state of the art reports 2. Dordecht: Springer; 2012.

5. Wyrzykowski M, Lura P. Controlling the coefficient of thermal expansion of cementitious materials: a new application for superabsorbent polymers. Cem Concr Comp. 2013;35(1):49-58.
6. Powers TC, Brownyard TL. Studies of the physical properties of hardened Portland cement paste. Skokie: Portland Cement Association, Research Laboratories; 1948.

7. Brouwers HJH. The work of Powers and Brownyard revisited: Part 1. Cem Concr Res. 2004;34(9):1697-716.

8. Hansen T. Physical structure of hardened cement paste. A classical approach. Mater. Struct. 1986;19(6):423-36.

9. Lura P, Jensen OM, van Breugel K. Autogenous shrinkage in high-performance cement paste: an evaluation of basic mechanisms. Cem Concr Res. 2003;33(2):223-32.

10. Jensen OM, Lura P. Techniques and materials for internal water curing of concrete. Mater Struct. 2006;39(9):817-25.

11. Wyrzykowski M, Lura P, Pesavento F, Gawin D. Modeling of water migration during internal curing with superabsorbent polymers. ASCE J Mater Civ Eng. 2012;24(8):1006-16.

12. Lura P, Friedemann K, Stallmach F, Mönnig S, Wyrzykowski M, Esteves LP. Kinetics of water migration. In: Mechtcherine V, Reinhardt HW, editors. Application of super absorbent polymers (SAP) in concrete construction. RILEM state of the art reports 2. Dordrecht: Springer; 2012. p. 25-37.

13. Wyrzykowski M, Lura P, Pesavento F, Gawin D. Modeling of internal curing in maturing mortar. Cem Concr Res. 2011; 41(12):1349-56.

14. Schröfl C, Mechtcherine V, Gorges M. Relation between the molecular structure and the efficiency of superabsorbent polymers (SAP) as concrete admixture to mitigate autogenous shrinkage. Cem Concr Res. 2012;42(6):865-73.

15. Hasholt MT, Jensen OM, Kovler K, Zhutovsky S. Can superabsorent polymers mitigate autogenous shrinkage of internally cured concrete without compromising the strength? Constr Build Mater. 2012;31:226-30.

16. Esteves L, Cachim P, Ferreira V. Mechanical properties of cement mortars with superabsorbent polymers. In: Grosse CU, editor. Advances in construction materials. Berlin: Springer; 2007. p. 451-62.

17. Winnefeld F, Barlag S. Calorimetric and thermogravimetric study on the influence of calcium sulfate on the hydration of ye'elimite. J Therm Anal Calorim. 2010;101(3):949-57.

18. Lura P, Winnefeld F, Klemm S. Simultaneous measurements of heat of hydration and chemical shrinkage on hardening cement pastes. J Therm Anal Calorim. 2010;101(3):925-32.

19. Zhang T, Yu Q, Wei J, Gao P, Zhang P. Study on optimization of hydration process of blended cement. J Therm Anal Calorim. 2012;107(2):489-98.

20. Taylor HFW. Modification of the Bogue calculation. Adv Cem Res. 1989;2(6):73-7.

21. Justs J, Wyrzykowski M, Deschner F, Winnefeld F, Bajare D, Lura P. Influence of superabsorbent polymers on hydration of cement pastes with very low water-to-binder ratio. Tagung Bauchemie, Gesellschaft Deutscher Chemiker, Fachgruppe Bauchemie. 11-12 October 2012: Dübendorf; 2012.

22. Tritik P, Münch B, Weiss WJ, Herth G, Kaestner A, Lehmann E et al. Neutron tomography investigation of water release from superabsorbent polymers in cement paste. International Conference on Material Science and 64th RILEM Annual Week; 6-10 September. Aachen; 2010.

23. Laboratory for Waste Management, Paul Scherer Institute. GEMS: Gibbs energy minimization software for geochemical modeling. 2012. http://gems.web.psi.ch/. Accessed Dec 2012.

24. Concrete/Construction Chemistry Laboratory, Empa. CEMDATA: thermodynamic data for hydrated solids in Portland cement system. 2012. http://www.empa.ch/cemdata. Accessed Dec 2012.

25. Langan BW, Weng K, Ward MA. Effect of silica fume and fly ash on heat of hydration of Portland cement. Cem Concr Res. 2002;32(7):1045-51. 
26. Winnefeld F, Becker S, Pakusch J, Götz T. Effects of the molecular architecture of comb-shaped superplasticizers on their performance in cementitious systems. Cem Concr Compos. 2007;29(4):251-62.

27. Taylor HFW. Cement chemistry. London: Academic Press Limited; 1990.
28. Danielson U. Heat of hydration of cement as affected by watercement ratio. Fourth international symposium of the chemistry of cement. Washington DC; 1960.

29. Siriwatwechakul W, Siramanont J, Vichit-Vadakan W. Behavior of superabsorbent polymers in calcium- and sodium-rich solutions. J Mater Civ Eng. 2012;24(8):976-80. 